\title{
BASIC OBLIGATIONS OF THE SERVICE PROVIDER
}

\author{
Mario Vojnić Hajduk ${ }^{36}$
}

\author{
https://doi.org/10.31410/itema.2018.98
}

\begin{abstract}
The question of determining the obligations of the service provider has great social, economic and legal significance. Service provider is the main provider of the service contract. Service contract is one of the most numerous contracts in practice. There is a general service contract for the provision of all services and a number of special service contracts for the provision of different special types of services. New special service contracts are being developed on a daily basis (for example, medical, information, financial services). They are more or less independent of the general service contract. There are a number of problems with service contracts. The first problem is non-existence of a developed definition of these contracts. Another problem is that it is difficult to determine which contracts are service contracts. The key problem is the lack of legal regulation in European countries for general and specific service contracts. Absence of legal regulation of rights and obligations of contracting parties (the service provider and the client), can lead to great differences in content of these contracts in practice, and can lead to the abuse of rights.

Due to the mentioned problems, the aim of this paper is to systematize the basic obligations of the service provider of the general service contract. The basic obligations of the service provider are: a pre-contractual duty to warn, obligation to perform a particular service, obligations regarding the transfer of the service (subcontracting), obligation of skill and care, obligation to achieve results, contractual obligation to warn the client, obligation to comply with client's directions, obligation to transfer results, obligation to accept a unilateral contract change. This paper is based on the analysis of the law of European countries. In this paper, as the main source DCFR was used. ${ }^{37}$
\end{abstract}

Keywords: obligations of the service provider, service provider, service contract, providing service, service

\section{INTRODUCTION}

$\mathrm{N}$

ext to the sales contract, the service contract takes a significant place. This contract is often concluded in various areas, such as medicine, information technology, agriculture, tourism, construction, sports, culture, art, financial sector. It is one of the basics of the economic system. At the same time, it is a classic and a modern contract. Continuous development of services leads to the development of the object of the contract. This also affects the determination of the rights and obligations of the contracting parties. Almost all business people, even those who sell, are engaged in providing some type of service. It is not possible to list all types of services. Examples for the classical services are design, building (construction), processing of goods, informational and advisory services, and for the modern services are web development, various medical treatment services. Specific legal rules have been developed for some specific services (construction, financial services and others). For

\footnotetext{
${ }^{36}$ University of Novi Sad, Faculty of Law Novi Sad, Serbia

${ }^{37}$ Principles, Definitions and Model Rules of European Private Law - DCFR: Draft Common Frame of Reference, prepared by the Study Group on a European Civil Code and the Research Group on EC Private Law, Book IV, Specific contracts and the rights and obligations arising from them, Part C, Services, Munich, 2009.
} 
other services, the rules of the general service contract apply. The provision of services is to provide the client with material and non-material benefits through the performance of intellectual and physical work. The person providing the service is called the service provider. For the provided service, he is entitled to a fee from the client. The successful determination of the basic obligations of the service provider is the key to understand this contract. This is the basis for the successful functioning of the traditional and modern service sector. Special obligations are characteristic of specific service contracts.

\section{BASIC LEGAL ISSUES OF THE GENERAL SERVICE CONTRACT}

General service contract (shortened: service contract) is a contract by which one contracting party, the service provider, commits to perform a particular service, while the other contracting party, the client, is obliged to pay the price of the service. The client is usually a user of the contracted service, but the user of the service (recipient of the service) may be a third party. Although a special form is usually not required for the conclusion of a contract, in practice, this contract is often concluded in written form. Service providers are economic entities engaged in the provision of services for compensation. Clients are other business entities or citizens. The service can be precisely contracted or the contract may contain elements on the basis of which the service can be determined. To determine the service of major importance are the general terms and conditions of the service provider. Unless otherwise agreed, the client is obliged to pay the compensation and when the compensation is not contracted. In such a situation, compensation is determined on the basis of the general terms and conditions of the service provider and based on the customs. Services of any type may be the subject matter of service contracts. The service may consist of one or more actions. It can be intellectual and physical work. It is important that actions are possible and that actions are not prohibited by law. The service may be provided on a one-time basis or may be provided within a specified period of time.

By its legal nature, this is a special (sui generis) contract of commercial law. It is a general contract with numerous subtypes. The legal norms governing this contract are of a general nature and they are applied whenever there are no specific legal norms for the subtypes of this contract. Subtypes (special service contracts) of this contract for example are contracts for construction, processing, storage, design, information or advice, treatment, transport, insurance, financial service, servicing. There are different approaches in terms of legal regulations across countries. In some countries in Europe, this contract is not at all regulated specifically. In some of them there is a similar contract that has a different name and may have some differences. ${ }^{38}$ In countries that know this contract explicitly, there are differences in the definition of a contract, in terms of the legal norms that regulate it, in subtypes and other differences. Contracts on financial services and insurance contracts are often considered to be separate (sui generis) commercial law contracts. ${ }^{39}$ Similar is the situation with the employment contract. What distinguishes these independent contracts is the lower autonomy of the will of the contracting parties. Sometimes it is very difficult to determine whether a particular contract is a service contract, considering the existence of many mixed contracts in practice. Contemporary contracts if they can 't be subsumed under other traditional contracts such as sales, lease, loan, will most often be a subtype of service contracts. This contract can be concluded as a standalone contract or it can be contained as independent agreement in one act with another contract

\footnotetext{
${ }^{38}$ For example see Articles 600 and 749 of the Serbian Law on Obligations; Закон о облигационим односима, „Сл. лист СФРЈ” бр. 29/78, 39/85, 45/89, 57/89, „Сл. Лист СРЈ” бр. 31/93

${ }^{39}$ DCFR, IV.C. - 1:102: Exclusions
} 
eg. with sales. The following definitions can be taken as examples of defining the term of this contract.

This is a contract under which one party, the service provider, undertakes to supply a service to the other party, the client, in exchange for a price, or otherwise than in exchange for a price. ${ }^{40}$ Because of the lack of legal regulation of this contract, a very important source of knowledge and law is DCFR. In a service contract, a person who promises service is obliged to perform the services promised, and the other party is obliged to grant the agreed remuneration. ${ }^{41}$ Similar definitions are contained in other legal sources. ${ }^{42}$ The fact is that legal sources often remain almost just on the definition of a contract. In the contract (Service Level Agreement-SLA) rights and obligations are established between the service provider and the client. ${ }^{43}$

\section{BASIC OBLIGATIONS OF THE SERVICE PROVIDER}

\subsection{Initial Consideration}

Rights and obligations of the contracting parties of service contract are divided into general and special. Special rights and obligations are contained in the subtypes of this contract. General (basic) rights and obligations are contained in the general service contract legal norms (state legislature, customs) or derive from specific legal norms for special service contracts. Under this contract, the rights of each party correspond to the obligations of the other party. Due to the scope of this paper, further general obligations of the service provider will be analyzed, with a necessary reference to some special rights and obligations. The basic obligations of the service provider are: a pre-contractual duty to warn, obligation to perform a particular service, obligations regarding the transfer of the service (subcontracting), obligation of skill and care, obligation to achieve results, contractual obligation to warn the client, obligation to comply with client's directions, obligation to transfer results, obligation to accept a unilateral contract change. In addition to these obligations, there are some others as well: obligation to allow client control, returning things given to use, submission of supporting documentation and others. Modern technologies create other modern obligations (first of all, IT services, medical services).

\subsection{Pre Contractual Duty to Warn}

The service provider is under a pre-contractual duty to warn the client if the service provider becomes aware of a risk that the service requested: may not achieve the result stated or envisaged by the client; may damage other interests of the client; may become more expensive or take more time than reasonably expected by the client.

This obligation is a pre-contractual obligation, which means that the service provider is obliged to notify the client until the contract is formed (more at: Contractual Obligation to Warn). Precontactual information duties are one of the hallmarks of modern EU consumer law. ${ }^{44}$ Notification obligation exists when the service provider becomes aware of mentioned risks. This is a subjective criterion. The service provider is presumed to be aware of the risks

\footnotetext{
${ }^{40}$ DCFR, IV.C. - 1:101: Scope, paragraph (1)

${ }^{41}$ Deutsch Bürgerliches Gesetzbuch (BGB) vom 18.08.1896. (www.juris.de), Article 611

${ }^{42}$ Kodex des Österreichischen Rechts-Lexis Nexis, Allgemeines Bürgerliches Gesetzbuch (ABGB), Wien 2015 , Article 1151

${ }^{43}$ M. H. Gillespie, J. R. Matthews, Handbuch Service Provider, Weinheim 2002, pp. 179.

${ }^{44}$ R. Schulze, J. Stuyck, Towards a European Contract Law, Munich 2011, pp. 49.
} 
mentioned if they should be obvious from all the facts and circumstances known to the service provider, considering the information which the service provider must collect about the result stated or envisaged by the client and the circumstances in which the service is to be carried out. ${ }^{45}$ This is an objective criterion. Risk always exist, so that the service provider is obliged to notify only the most important risks. Service provider can (doesn't have) to notify the client about the risks, if the client already knows of the risks or could reasonably be expected to know of them. The client can't reasonably be expected to know of a risk merely because the client was competent, or was advised by others who were competent, in the relevant field, unless such other person acted as the agent of the client.

The information about risk given to the client must be clear and sufficient in accordance with the circumstances of the case. If the contract is concluded in writing, the obligation to notify should be given in writing. After giving notice, a reasonable time should be left to the client to make a declaration about the conclusion of the contract.

The service provider is obliged to inform about three types of risks. The first are the risks, due to which the service can 't achieve two types of results; stated or envisaged by the client. When the service provider is obliged to perform the results envisaged by the client, is a factual question. A clear situation is when the parties are in long-term business relationships, because then the service provider better know the business intentions of the client. The second are the risks that the service requested may damage other interests of the client. Other interests are the business interests of the client, to whom provided service can cause unusual damage. For example, when the provision of the service causes a necessary termination of the clients work in a longer period of time. Usually, this does not apply to indirect damage, for example, for a cheaper price of service of other service providers. The third are the risks that the service requested may become more expensive or take more time than reasonably expected by the client. In this situation the price of the service is not defined as a fixed price, but it is calculated on the basis of the factors for example working hours, price of materials, etc. If the service provider does not inform the client of the specified risks, he will be late with other obligations or will not properly fulfill other obligations.

From the rule of equality of parties arises, the client's obligation to warn. The client is under a pre-contractual duty to warn the service provider if the client becomes aware of unusual facts which are likely to cause the service to become more expensive or time-consuming than expected by the service provider or to cause any danger to the service provider or others when performing the service.

\subsection{Obligation to Perform a Particular Service}

From the definition of a contract, the main obligation of the service provider arises. It is the obligation to perform a particular service. The service must be performed in a manner, on time and in the place as agreed. It is best to arrange all these questions in detail. In the absence of contractual rules, formal legal sources are applied. For determining the time and place of service, cash and non-cash obligations are distinguished. These contracts are often concluded by contracting parties from different countries. Then the question of legal sources is further complicated. Modern services, are often complex services. It is not enough to determine them by name, but they need to be described. General terms of service of service providers can often

\footnotetext{
${ }^{45}$ DCFR, IV.C. - 2:102: Pre-contractual duties to warn, paragraph (6)
} 
be interpreted in many ways. Clients, are often with their content introduced only in the event of a dispute. Abuse of the right is prohibited during the execution of the service.

When performing the service, the service provider should take into account the best interests of the client and to cooperate with him. This basic obligation is concretized with the obligation of skill and care. For this and other obligations, some other special rules may have an advantage in the application (Mandate, special services, and similarly). Some services are characterized by other specific obligations. Such are financial services (for example bank secret). To enable the service provider to perform the obligations under the contract, the client is obliged to cooperate, for example to give information, directions, materials.

\subsection{Subcontracting}

The service provider may subcontract the performance of the service without the client's consent. This may relate to the service in whole or in part. The service can be performed by one or more other persons. When a personal performance is required by the contract, the service provider needs the consent of the client. Assuming this is an inter parties contract, but may be designated by the contracting parties as a intuitu persone contract. Client's consent must be clear and given in the form of a contract. The consent may be given before, during and after the service is performed. Consent may be explicit or tacit, e.g. accepting the execution of the service by another provider.

Without the client's consent, any subcontractor engaged by the service provider, must be of adequate competence. The issue of adequate competence is a matter of fact. This is an unclear legal concept, which is closely connected with the client's consent. It is also connected with the obligation of skill and care and with one special obligation of the service provider. Therefore, the service provider must ensure that any tools and materials used for the performance of the service are in conformity with the contract and the applicable statutory rules, and fit to achieve the particular purpose for which they are to be used. In so far as subcontractors are nominated by the client, the responsibility of the service provider is governed with rules in part „Directions of the client" and „Contractual obligation of the service provider to warn".

\subsection{Obligation of Skill and Care}

The service provider must perform the service with the care and skill which a reasonable service provider would exercise under the circumstances and in conformity with any statutory or other binding legal rules which are applicable to the service. This is an obligation of skill and care. Care and skill must be reasonable; in the provision of the service there should be no significant deviation from the objectively common provision of the service. If the service provider professes a higher standard of care and skill the provider must exercise that care and skill. Service providers are often experts, who provide services professionally in accordance with the rules of profession and science. Such features of service providers are the basis for clients to conclude contracts with them. The service provider must exercise the care and skill expressed in standards which have been set by a relevant authority.

The obligation of skill and care require in particular the service provider to take reasonable precautions in order to prevent the occurrence of damage as a consequence of the performance of the service. This also mutatis mutandis applies if damage has occurred. Damage refers to damage to the client, but also to damage to other persons, things and the environment. This comes out from the general principle prohibition of causing other damage. Care and skill, 
among other things, include information to the client whether the service provider is a business, amount of compensation, execution of the service within a reasonable time. This is a general obligation that includes usual practices that are not explicitly contracted or arise from various legal rules, rules of profession and science. Some services may require the service provider to detect conflicts of interest. The service provider may be in the obligation of keeping a business secret (for example: Consulting contract).

\subsection{Obligation to Achieve Results}

Execution of the service itself is not sufficient. The service provider must achieve the specific result (or results) stated or envisaged by the client at the time of the conclusion of the contract. The supply of a service can be described as a process by which the service provider performs work undertaken according to the particular wishes and needs of the client, in order to achieve a particular result. ${ }^{46}$ Specific stated result is an explicit statement of the client's will, which clearly stems from the contract. An example of a specific result is that the service is suitable for a specific purpose of the client. In order for this result to be binding on the service provider, it must be declared until the conclusion of the contract. After the conclusion of the contract, a special consent of the service provider is required. The result of the service must be reached by the time agreed to perform the service (unless something else comes out from the custom; medical services and similarly). The specific result envisaged by the client is a result which the client could reasonably be expected and the client had no reason to believe that there was a substantial risk that the result would not be achieved by the service. For example, when a client is in long-term business relationships with a service provider, he can expect the achievement of earlier results. This doesn't apply when there was a mentioned substantial risk for which he knew or had to know. Substantial risk is a risk of considerable importance. It is a risk that should be reasonably considered as a risk that can prevent the outcome of the results.

Since clients often do not have the necessary knowledge about the service, in determining the result of the service, cooperation of the service provider is required. This primarily refers to the collection of information about the client's opportunities, needs and getting to know the client with the appropriate service capabilities. The price of these actions can be calculated in the price of the basic service or as a special service price. For example, such a service is a loan processing service. The service provider may also provide suggestions to the client regarding a service, that in his opinion are suitable for the client.

The client must notify the service provider if he becomes aware during the period for performance of the service that the service provider will fail to achieve result. The client is presumed to be so aware if from all the facts and circumstances known to the client without investigation the client has to be so aware.

\subsection{Obligation to Comply with Client's Directions}

The service provider must follow directions of the client regarding the performance of the service. Directions can be informative or binding. He must follow the directions which are part of the contract itself or are specified in any document to which the contract refers. These other directions are not physically contained in the contract as a document, but legally they are the content of the contract. These are the client's directions regarding the fulfillment of the obligations of the service provider. For example, a direction to observe the deadline for the

\footnotetext{
${ }^{46}$ M. Barendrecht, C. Jansen, M. Loos, A. Pinna, R. Cascao, S. van Gulijk, Service Contacts, Munich 2007, pp. 202.
} 
obligation. The service provider must also follow the directions which result from the realization of choices left to the client by the contract. It is about specifying the service (quantity, quality, time and similarly), but not about the choice of its kind, unless otherwise agreed. This also applies to the directions which result from the realization of choices initially left open by the parties. It is in the interest of the client to make the selection as soon as possible. If the client fails to issue the directions, the service provider should invite him to do so within a reasonable time. In emergencies, the provider of the service must act in the best interest of the client. As soon as possible, he must seek further instructions. Clients often do not give instructions, because they do not have adequate knowledge.

\subsection{Contractual Obligation to Warn}

Contractual obligation of the service provider to warn is an obligation arising from the concluded contract. The service provider is presumed to be aware of risks mentioned later, if they should be obvious from all the facts and circumstances known to the service provider without investigation. Obvious risks are those seen without special examination of their existence. The service provider must warn the client if the service provider becomes aware of a risk that the service requested: 1. may not achieve the result stated or envisaged by the client at the time of conclusion of the contract, 2. may damage other interests of the client, 3. may become more expensive or take more time than agreed on in the contract. Service provider can find out about the risks during the preparation of the service and later, based on contact with the client, from third parties and similarly. The obligation to warn does not apply if the client already knows of the risks or could reasonably be expected to know of them. The client cannot reasonably be expected to know of a risk merely because the client was competent, or was advised by others who were competent, in the relevant field, unless such other person acted as the agent of the client. Just a notice of the service provider is not enough. The service provider must take reasonable measures to ensure that the client understands the content of the warning. A warning in writing is generally not required ${ }^{47}$ The warning must be serious and complete, customized to client characteristics. The type of risk, its quality, quantity, consequences and other important risk characteristics must be described. The warning must be given within a reasonable time and in a reasonable way.

\subsection{Obligation to Transfer Results}

Achieving the result or results of the service is not enough. For the execution of the service, the service provider receives a fee from the client. Where the service provider is a business, a price is payable unless the circumstances indicate otherwise. Therefore, the service provider is obliged to transfer (hand-over) the results of the service to the client. In some situations, the execution of the service implies the transfer of results (for example medical services). What is valid for the execution of the service is also valid for the transfer of results. Transfer of results can be considered as a special obligation or as the final stage in the execution of the service.

\subsection{Obligation to Accept a Unilateral Contract Change}

Either contracting party may by notice to the other party, change the service to be provided, if such a change is reasonable taking into account: the result to be achieved, the interests of the client, the interests of the service provider, the circumstances at the time of the change. In DCFR

\footnotetext{
${ }^{47}$ M. Barendrecht, C. Jansen, M. Loos, A. Pinna, R. Cascao, S. van Gulijk, Service Contacts, Munich 2007, pp. 247.
} 
a change is regarded as reasonable only in four cases. ${ }^{48}$ The other party has to respect the changes to the contract. For example a change is regarded as reasonable if it is required by a change of circumstances which would justify a variation as variation or termination by court on a change of circumstances (performance of a obligation becomes so onerous because of an exceptional change of circumstances that it would be manifestly unjust to hold the debtor to the obligation). Any additional price due as a result of the change has to be reasonable and is to be determined using the same methods of calculation as were used to establish the original price for the service. The original price is the contracted price. The new price changes the original price. The new price may be higher or lower than the original one. The dispute over change will be made by the competent court. In so far as the service is reduced, the loss of profit, the expenses saved, and any possibility that the service provider may be able to use the released capacity for other purposes are to be taken into account in the calculation of the price due as a result of the change. The change may also refer to the time and place of service, the quality and quantity of the service. Possibility of unilaterally changing the type of service is a factual question.

\section{CONCLUSION}

There is a general service contract and there are special service contracts. Principally, by its legal nature special service contract is a subtype of the general service contract. The contracting parties are the service provider and the client. Obligations from the general service contract (basic obligations) are also the obligations of the special ones, unless legal norms exclude some obligations. The service provider has the main contractual obligation to perform the service and he has other related obligations.

\section{REFERENCES}

1. M. Barendrecht, C. Jansen, M. Loos, A. Pinna, R. Cascao, S. van Gulijk, Service Contacts, Munich, 2007.

2. M. H. Gillespie, J. R. Matthews, Handbuch Service Provider, Weinheim, 2002.

3. R. Schulze, J. Stuyck, Towards a European Contract Law, Munich, 2011.

4. Principles, Definitions and Model Rules of European Private Law - DCFR: Draft Common Frame of Reference, prepared by the Study Group on a European Civil Code and the Research Group on EC Private Law (Book IV, Specific contracts and the rights and obligations arising from them, Part C, Services), Munich, 2009.

5. Deutsch Bürgerliches Gesetzbuch (BGB) vom 18.08.1896. (www.juris.de)

6. Kodex des Österreichischen Rechts-Lexis Nexis, Allgemeines Bürgerliches Gesetzbuch (ABGB), Wien, 2015.

7. Zakon o obligacionim odnosima, „Sl. List SFRJ” br. 29/78, 39/85, 45/89, 57/89, „S1. List SRJ" br. 31/93.

\footnotetext{
${ }^{48}$ DCFR, IV.C. - 2:109: Unilateral variation of the service contract, paragraph (2)
} 